\title{
Cloud Computing and the Business Consequences of ERP Use
}

\author{
Mozammel-Bin-Motalab \\ Master in Information Technology \\ IIT, University of Dhaka \\ Dhaka, Bangladesh
}

\author{
Shoyeb Al Mamun Shohag \\ MS in Computer Networks \\ $\mathrm{KTH}$, The Royal Institute of Technology \\ Stockholm, Sweden
}

\begin{abstract}
A Cloud Computing system is intended to improve and automate the controlling single point operations. By using a single point of control, this goal is accomplished through the elimination of duplicate entry and the contribution of data integrity, detailed drilldown, simple training, manageable support, minimal IT maintenance, easy upgrades and reduced costs. Overall, the advantages of cloud computing usage fulfill the original intentions of business as it allows process manufacturers to manage their business as simply and efficiently as possible. Enterprise Resource Planning (ERP) software is designed to improve and auto-mate business processes operations. However, there are many unnecessary administrative, procedural costs and delays often associated with this practice. Examples include duplicate data entry, data corruption, increased training, complicated supplier relations, greater IT support and software incompatibilities. Purpose of this system is Single Point of Control, Duplicate Entry Elimination, Data Integrity, Detail Drill Down, Basic Training, Manage Support, Security, Minimal IT Maintenance, Easy Upgrades, and Reduce Costs etc.
\end{abstract}

\section{General Terms}

Software Engineering

\section{Keywords}

Cloud, ERP, Business Consequence.

\section{INTRODUCTION}

Now every organization are in a global world where all the business are very much familiar to use technology for prosper, prospect as well as daily work. Business has willing to do all the works in respect of saving money, time and energy and also for the fortification of their assets and belongings in an effective and efficient way.

ERP software is very much dependent on Software platform, Database, Intelligence, security and other third party software. Some time it is not possible for single software development firm to treat every dependency and feature in a same manner [11].

Cloud computing can ensure the benefit of both vendor and the business user. This is only part of the challenge, though. Forecasted growth will generally have at least some impact on IT operating costs. Here assumed that cloud is not only created for the ERP the total support and establishment of ERP will be from a cloud [1].
Organizations have goals to implement this proposed system let the business organization define their business process, no dependency on predefined ERP business flow. To support and develop a cost effective and user friendly Cloud based ERP system providing high quality and robust system dependency. There is a multiple venture idea to support and maintain the system. This system can offer reliable and paramount service to the IT management for business organizations [3].

The rest part of this paper have been structured as, literature review has been point out in section 2. Section 3 holds the traditional ERP with business cases. Our proposed cloud computing system has been placed in section 4. A comparison among present ERP flowchart and proposed ERP flowchart has been given in section 5. Discussion and analysis part is in section 6 . A conclusion has been made in section 7 .

\section{LITERATURE REVIEW}

The authors in [1] mainly focused on cloud, cloud computing and its myriad application. They describe various cloud computing paradigm and types of clouds those includes public cloud, private cloud, community cloud and hybrid cloud. A cloud computing architecture has been describes with existing features. Finally, they have deployed a cloud computing system and showed the feature that differentiates with the existing cloud computing process.

In [2], the author works with cloud computing for educational system and more specifically on the security issues of public clouds. At the end, he has provided a guide line to develop a cloud computing for education system. Finally the author suggest few issues to develop a educational cloud computing system those includes working principles, significance of development, growth of the system and implications of the education.

An investigation on cloud computing has been done in [3]. The authors tested the performance of cloud computing systems running in a virtual environment via remote, and wide-area network resource access. Their test result showed that virtual environment system having short job runtime of a work flow has the good compute time scale that can be effected by resource scheduling delays and wide area communications.

According to [4], the authors' works on cloud computing system for GIS (Geographical Information System) and they have made a large evaluation on cloud computing approach to GIS. Finally, a multi-tiered architecture for GIS Cloud System has been proposed that holds mainly two components those are GIS cloud 
web interface and GIS server. The GIS server has been divided into five sub layer to get the best performance from the shared resource like databases, configuration, server logic, server side utilities, communication interfaces and high powered processing infrastructure.

Importance and advantage of cloud computing on web application have been showed in [5]. The author's remarks on few issues related to cloud computing for web application like price, simplicity, flexibility, collaboration, privacy and security. They also discussed how power loss occurred with the component of computer and they think that distributing highvoltage DC power throughout the data centre may reduce the loss.

The authors in [6] focused on frame work of future egovernment for cloud computing. They observed that present egovernment frame work is not able to map all users' criteria. They have been proposed an new effective e-government frame work which is more intelligent and able to filled up all user criteria's.

An algorithmic approach and eco-friendly cloud computing have been implemented and tested in [7]. They also works on green cloud computing. The green cloud empathises on the power consumption by the cloud computing approaches. They have remarks on proper security management system for their proposed of cloud computing approaches for future endeavours.

A mathematical model for cloud computing has presented in [8]. Where the authors implemented a mathematical model based on marketing oriented cloud computing. An algorithm also been implemented from the mathematical model. They have been tested their proposed system setting up a private cloud based on Ubuntus 10.04 Server edition. Their test result shows that as stochastic demand gradually increases, the proposed objective function slowly increases and provides more optimized value when the stochastic demand is within a moderate to maximum range although they didn't find best performance when maximum stochastic demand held's.

According to [12], the authors focused on Software as a service providers (cloud user) and cloud providers. They have defined cloud, is the combination of data centre hardware and software. They also define the public cloud as, when a cloud have prepared with the pay-as-you go manner for public and these services are sold called utility computing. They have predict cloud computing will grow fast and developer should account on how smoothly a single virtual Machine serve the services. In addition, they also remarks three points those includes scale down and up of application software, upgrading of infrastructure software and hardware system (putting idle portions of the memory, disk, and network into low power mode, processors should work well with VMs, flash memory should be added to the memory hierarchy, and LAN switches and WAN routers must improve in bandwidth and cost).

In [13], author works on cloud computing because of the migration of software system to distance server that is accessible remotely. They have shown the evolution of cloud computing and predicts the future of cloud computing is less than clear, showing few example that treated as directions. They have mention about WordStar for the web that first attracted people to cloud computing. They also mentioned about Google docks as earlier developed application for WordStar. In enterprise cloud computing, the first was Salesforce.com that was founded in 1999. They also focused on cloud infrastructure and cloud OS.

The author in [14], focused on the concept of cloud computing, addressed few issues related to research topics and a cloud implementation that works with VLC technology. The author shown his experience with VLC technology is excellent and he is working on additional functionalities and features for future improvement of cloud frame work of cloud computing.

The authors in [15], initially defined the cloud computing and they have remarks three aspect from hardware point of view like, the appearance of infinite computing resources available on demand, the elimination of an up-front commitment by cloud users and the ability to pay for use of computing resources on a short-term basis as needed. They have discussed about the cloud computing economies and showed the benefits of cloud computing over conventional data centre. They also finds out top ten obstacles and opportunities for growth of cloud computing.

\section{BUSINESS CASE}

To make expenses predictable, and cloud computing-based solutions provide an opportunity to do so. Centralized ERP and other venture to support the system will reduce the high cost for the Business organization. It will ensure the performance, reliability, robustness which is very necessary for a business organization. Various ventures will introduce to maintain and support the system. Identical performance will be provided to various business organization and centralized data base for everyone.

Infrastructure is expensive. Without the scale available to larger businesses, in fact, it's disproportionately costly. Even when there aren't unexpected outages, basic maintenance, and growth considerations can lead to necessary increases in IT budget, consuming capital that could invest in other projects instead.

The opening up of Small and Medium Enterprises (SMEs) market for ERP. The high IT infrastructure and ERP Implementation project costs has acted as entry barrier. The "Cloud Computing" model will offer very economical way to embrace and implement ERP for these companies.

\subsection{ERP Methodology}

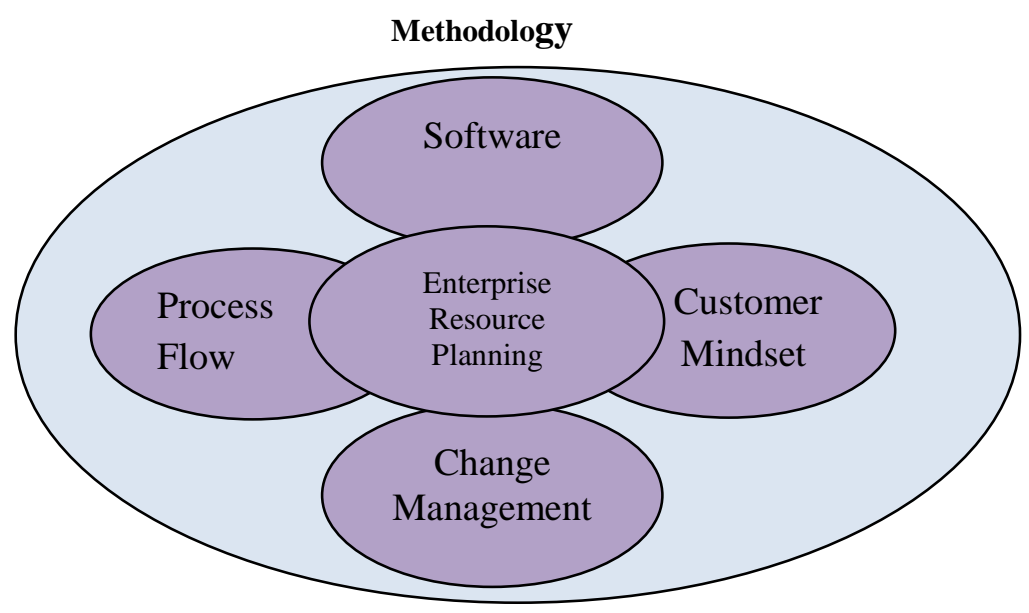

Fig 1: Traditional ERP 
Traditional ERP has a methodology that consists of four components. The software component is the expression of the ERP. The process flow is defining the flow of information among the ERP. Customer mindset set the work flow of an organization. This work flow set up will be done by compromising in between the before implementation way of work and after implementation way of work. Lastly, change management needed different state of ERP i.e. customer attitude resistance and any kind of business process changes. Proposed system has some distinctive change that explained in the next section [10].

\section{PROPOSED SYSTEM FEATURES}

Defining the business process will be on the safe side of business organization. Business organization will follow a standard business process, which can be defined by ERP system. Our proposed system for Cloud computing has been placed in Fig 2 bellows.

Definition and connectivity of database system will be provided by vendor. Business organization has to have an option to choice database depending on their budget and intelligence they need. Database definition and specification is defined such a way that different business organization has an access to their own database. Reporting tools will be general for all business organization. Business organization can define their simple reports by their own skill. If the report is complex, business organization will consider vendor to provide them support. Report integration (RI) will be provided by the vendor to get reliable and specific report for the organization.

Security is a vast issue for ERP. Vendors will provide security to their cloud, application and database separately. Security and encryption may be provided by the different vendor to make a reliable system.
Some time ERP need integrated hardware mostly to read Infrared tag, RFID (Radio Frequency Identification) tag etc. These integrated hardware driver software will be supported by the cloud system.

To implement most sophisticated ERP system there is a vast dependency on a reliable Operating system. Vendor will chose an operating system to be on cloud and give an elevated performance to the Business organization. This operating system should be easily configurable and maintainable by vendors. Operating system is also very important to support third party software.

Cloud server should be robust and reliable in its performance. IT service of different organization will be provided in a single point. As Cloud Computing becomes more mature, there will be opportunity for ERP Service Vendors on two fronts. Existing big companies will start migrating to "Cloud" to reduce capital and operational IT expenditure.

All IT support, Maintenance and training provided by the vendor end. Traditional systems are very high at cost in these issues. Cost will be nominal. Every R\&D dependent on the cloud environment will be pointed on the single point service.

The ERP cloud will be access by Administrator, User and Vendors. Vendor will create and support the cloud to give its optimum performance to the Business user. Version controlling and upgrades will centrally provided by the vendors. Administrators from both end - business organization and vendor will define the business process, check the performance, reliability and robustness of ERP. User of the Cloud ERP system will make an efficient use of the system. This end user will authenticate and corroborate that the system is fit for their purpose. 


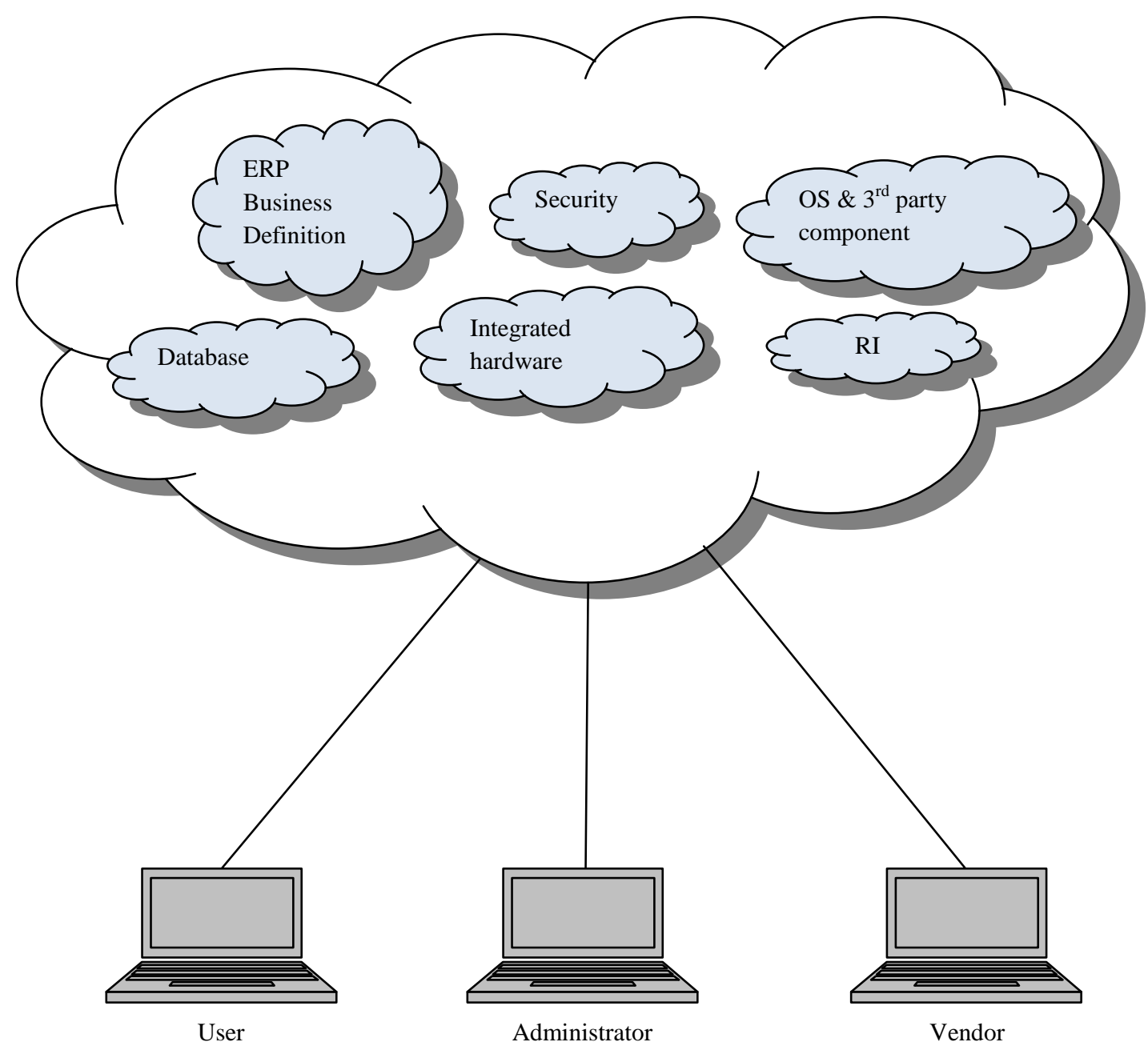

Fig 2: Cloud based ERP (Proposed system)

\section{ERP}

\section{IMPLEMENTATION}

\section{TECHNIQUE}

Traditional ERP implementation plan has been studied and point out with the sub section. A cloud based ERP implementation plan has designed and showed with the sub section of this part that gives us a clear understanding and differentiates from each other.

\subsection{Traditional ERP Implementation Plan}

According to [9], the flow chart of traditional ERP system has mentioned bellows in the Fig 3 .

\subsection{Proposed Cloud ERP Implementation}

\section{Plan}

Our proposed cloud based ERP flow chart has given bellows in the Fig 4. 


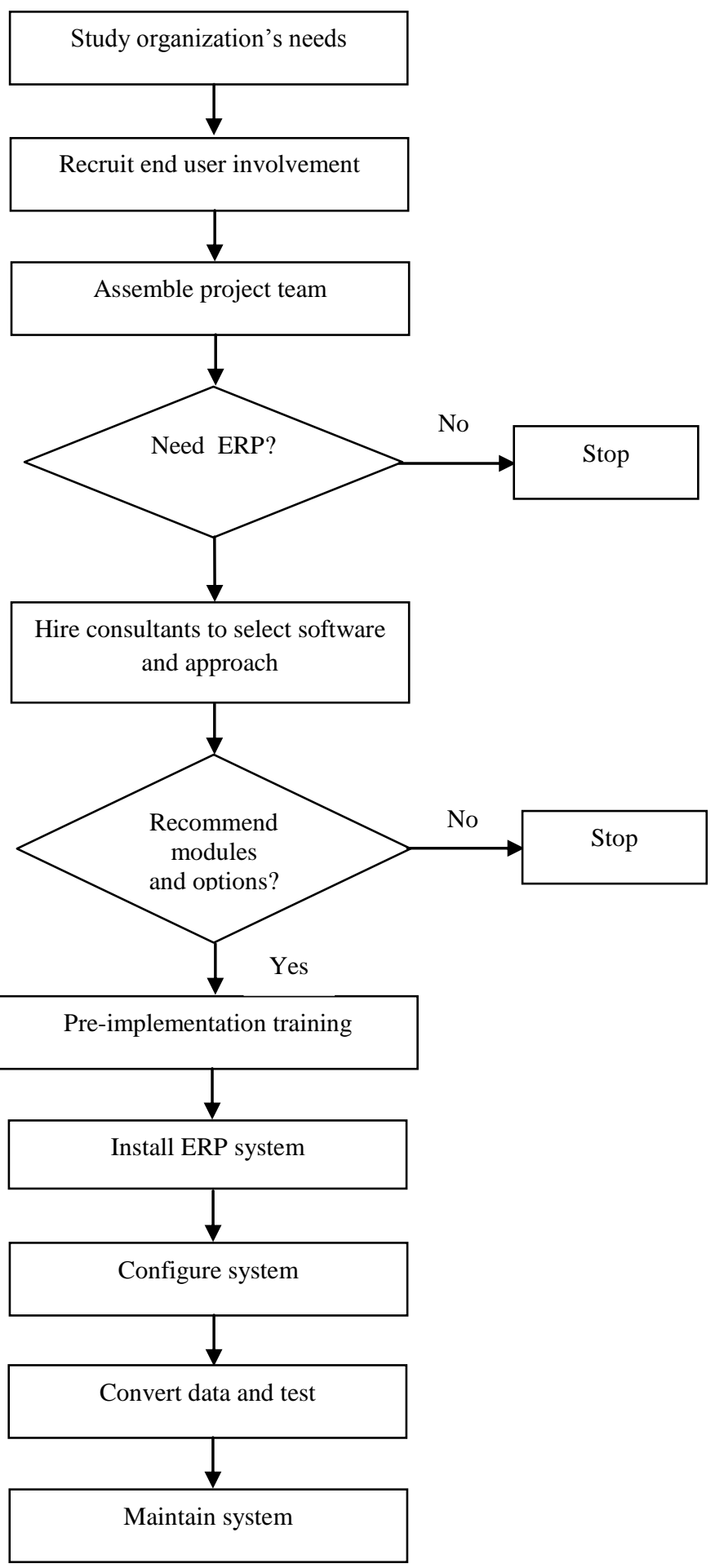

Fig 3: Traditional ERP flow chart [9]

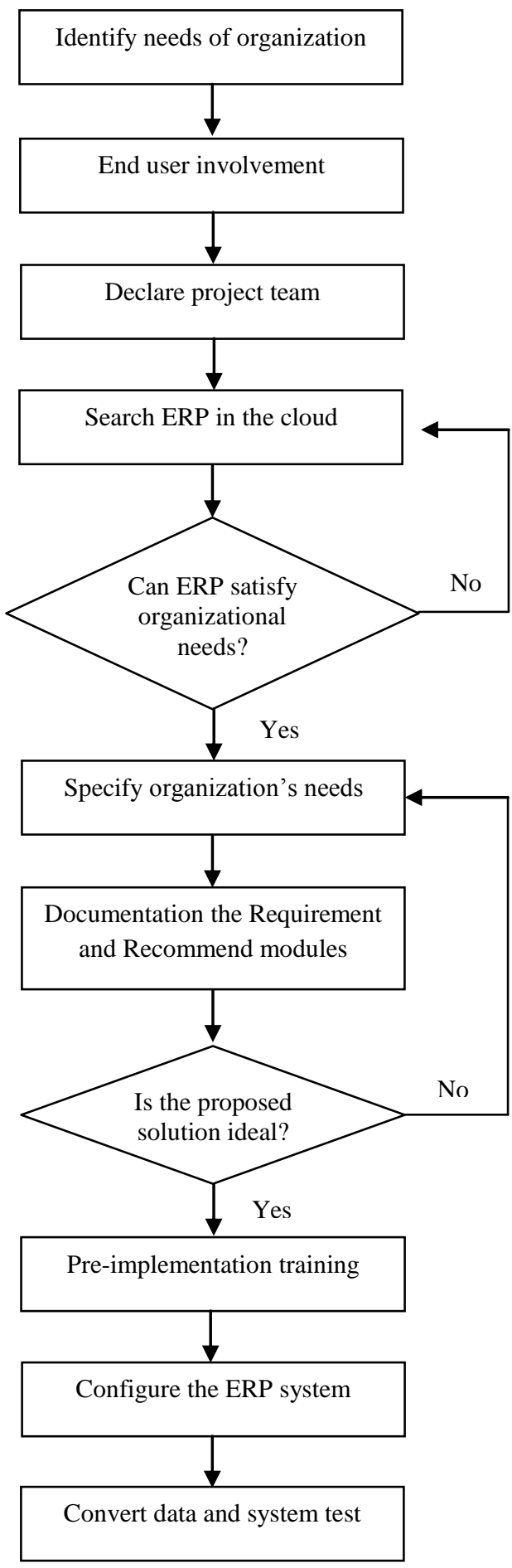

Fig 4: Proposed Cloud based ERP flowchart 


\section{DISCUSSION AND ANALYSIS}

Earlier ERP systems are implemented on the platform of premises of a company's server, thus hosted systems are at their own services. Proposed system allows implementing the ERP into a cloud that is managed by other vendor. Proposed system has an efficient option to choose business organization's own business flow as they recently acting on. More precisely we can say that, Cloud ERP has its own flow. But a business organization can also define their business by themselves. On the other hand ERP provider can define a standard business flow that can be followed by the business organization.

ERP packages are also has options to choose from cloud during ERP software selection by the business organization. Technically Cloud ERP is simple to deploy, organization need not to bear additional server and other dependent costs. It is also easy and quick to implement an ERP to a business organization. On the other hand, traditional ERP experience a challenge to deploying and maintenance.

Traditional ERP is very much controllable by the business organizations, because it is under their supervision. Again cloud ERP controlling depends on the support of the vendor. Vendor can ensure the control of ERP on be half of business organizations.

Traditional ERP has an easy accessibility both technically and user prospect. It does not depends on internet rather intranet. Alternatively, cloud ERP depends on internet. So if the internet bandwidth is low or it's technically departed then support cloud ERP is in trouble.

Some specific and desirable quality of the traditional ERP and Cloud ERP are listed bellow in the Table 1.
Table 1: Comparison among Traditional ERP and Cloud ERP

\begin{tabular}{|c|c|c|}
\hline Quality & Traditional ERP & $\begin{array}{l}\text { Cloud ERP } \\
\text { (Proposed) }\end{array}$ \\
\hline Deployment & Local server & Cloud Server \\
\hline $\begin{array}{l}\text { Defining } \\
\text { Business Flow }\end{array}$ & $\begin{array}{l}\begin{array}{l}\text { Defined by } \\
\text { ERP } \\
\text { developer } \\
\text { business }\end{array} \\
\text { arganization specific. } \\
\text { Organization } \\
\text { Specific }\end{array}$ & $\begin{array}{l}\text { Define by both, } \\
\text { ERP developer } \\
\text { and Business } \\
\text { organization. Flow } \\
\text { specific. }\end{array}$ \\
\hline $\begin{array}{l}\text { Implementation } \\
\text { cost }\end{array}$ & High & Low \\
\hline Ongoing cost & Relatively high & Low \\
\hline Control over ERP & Easily controllable. & $\begin{array}{l}\text { Relatively tough to } \\
\text { control. Cause } \\
\text { ERP is in the } \\
\text { cloud. }\end{array}$ \\
\hline Customization & $\begin{array}{l}\text { Not open for } \\
\text { business } \\
\text { organizations }\end{array}$ & $\begin{array}{l}\text { Open for business } \\
\text { organizations }\end{array}$ \\
\hline Support cost & Relatively high & Low \\
\hline Integration & $\begin{array}{l}\text { Dependent on } \\
\text { vendors. }\end{array}$ & $\begin{array}{l}\text { Depends on the } \\
\text { vendor, but it can } \\
\text { support centrally } \\
\text { so many other } \\
\text { business } \\
\text { organization might } \\
\text { supported at a } \\
\text { time. }\end{array}$ \\
\hline Licensing cost & High & Low \\
\hline $\begin{array}{l}\text { ERP update, } \\
\text { modification }\end{array}$ & Costly. & $\begin{array}{l}\text { Low cost, cause it } \\
\text { is maintained } \\
\text { centrally }\end{array}$ \\
\hline $\begin{array}{l}\text { Dependency on } \\
\text { internet }\end{array}$ & No & Yes \\
\hline Audit and Trial & $\begin{array}{l}\text { By organizational } \\
\text { prospect, it is easy }\end{array}$ & $\begin{array}{l}\text { Relatively } \\
\text { complex. }\end{array}$ \\
\hline $\begin{array}{l}\text { Version } \\
\text { controlling }\end{array}$ & Relatively complex & Easy \\
\hline
\end{tabular}




\section{ACKNOWLEDGEMENT}

First, our thanks to Almighty "ALLAH" to keep us safe and sound for the time being. We are also thankful to our parents for their unbounded love and blessing for ever and friends for their great cooperation.

\section{CONCLUSION}

Our aim was to design a cloud based ERP business consequence that has been done and discussed in the previous sections. We have also showed how our proposed cloud based ERP system would be easy of use and cost effective comparing with present ERP flowchart. The weakness of our proposed ERP model has also been discussed .Considering the cost effectiveness and ease of use, our proposed system has a better prospect in the filed of ERP based automatic business system. The Cloud Computing paradigm is yet to prove itself as a reliable and mature IT services model which is not only promises to cut the IT infrastructure costs but will also provide businesses to reap benefits from faster implementation of IT projects, improved agility to adjust to ever changing market environment and reduce IT costs at the same time. Confidently make that path to finish the research according to a project plan and work schedule managing the risks and flaws.

\section{REFERENCES}

[1] N. Ram Ganga Charan , S. Tirupati Rao , Dr .P.V.S Srinivas, Deploying an Application on the Cloud, International Journal of Advanced Computer Science and Applications, Vol. 2, No. 5, 2011

[2] P.Shanthi Bala, Intensification of educational cloud computing and crisis of data security in public cloud. , International Journal on Computer Science and Engineering, Vol. 02, No. 03, 2010, 741-745.

[3] M. Sudha, M. Monica, Investigation on Efficient Management of workflows in cloud computing Environment, (IJCSE) International Journal on Computer Science and Engineering, Vol. 02, No. 05, 2010, 1841-1845

[4] Muzafar Ahmad Bhat et al, Cloud Computing: A solution to Geographical Information Systems (GIS), International Journal on Computer Science and Engineering (IJCSE), ISSN : 0975-3397 Vol. 3 No. 2 Feb 2011

[5] Liladhar R. Rewatkar, Ujwal A. Lanjewar ,Implementation of Cloud Computing on Web Application, International Journal of Computer Applications (0975 - 8887) Volume 2 - No.8, June 2010.

[6] K.Mukherjee, G.Sahoo, Cloud Computing: Future Framework for e-Governance, International Journal of
Computer Applications (0975 - 8887), Volume 7- No.7, October 2010

[7] K Mukherjee, G.Sahoo , Green Cloud: An Algorithmic Approach, International Journal of Computer Applications (0975 - 8887) Volume 9- No.9, November 2010.

[8] K. Mukherjee, G.Sahoo ,Development of Mathematical Model for Market-Oriented Cloud Computing ,International Journal of Computer Applications (0975 8887) Volume 9- No.11, November 2010.

[9] Dr. Linda K. Lau, Longwood University, llau@longwood.edu, developing a successful implementation plan for ERP, IACIS 2003.

[10] Bundit Wonglikphai, Project Management in Enterprise Resource Planning (ERP) Implementation, http://www.umsl.edu/ sauterv/analysis/f06Papers/Wonglip hai/

[11] Jae-won Park and Nam-Yong Lee, A Conceptual Model of ERP for Small and Medium-Size Companies Based on UML, IJCSNS International Journal of Computer Science and Network Security, VOL.6 No.5A, May 2006.

[12] Michael Armbrust, Armando Fox, Rean Griffith, Anthony D. Joseph, Randy H. Katz, Andrew Konwinski, Gunho Lee David A. Patterson, Ariel Rabkin, Ion Stoica, Matei Zaharia ,Above the Clouds: A Berkeley View of Cloud Computing, http://www.eecs.berkeley.edu/Pubs/TechRpts/2009/EECS2009-28.html, February 10, 2009

[13] Brian Hayes, Cloud computing, DOI: 10.1145/1364782.1364786, http://bit-player.org/bph publications/CACM-2008-07-Hayes-cloud.pdf

[14] Mladen A. Vouk, Cloud Computing - Issues, Research and Implementations, http://hrcak.srce.hr/cit_ojs/index.php /CIT/article/viewFile/1674/1378

[15] MiChAEL ARmBRuSt, Armando fox, Rean Griffith, Anthony D. Joseph, Randy Katz, Andy Konwinski, Above the Clouds: A Berkeley View of Cloud Computing, Technical Report No. UCB/EECS-2009-28, http://www.eecs.berkeley.edu/Pubs/TechRpts/2009/EECS2009-28.pdf

[16] Gunho Lee, David Patterson, Ariel rabkin, ion Stoica, And matei zaharia, A view of cloud computing, http://delivery.acm.org/10.1145/1730000/1721672/p50armbrust.pdf 